\title{
Efficacy of Intravenous Immunoglobulin in the Management of Guillain Barre Syndrome
}

\author{
MM RAHMAN ${ }^{\mathrm{a}}$, K AHMED ${ }^{\mathrm{b}}$
}

\begin{abstract}
Summary:
A total number of 40 respondents consisting of 20 subjects of Guillain barre syndrome in each group treated with intravenous immunoglobulin (case) and without IVIg were selected during the study period. Out of 20 cases, 12 (60\%) were male and 8 (40\%) were females, ratio 1.5:1. Majority of the cases were presented at second or third decade of life. In control group, 11 (55\%) were male and 9 (45\%) female, ratio 1.22:1. Majority of the patients had history of upper respiratory tract infection or acute gastroenteritis 1 4 weeks preceding illness. All the patients had flaccid paralysis in all four limbs with some sensory features without bowel and bladder involvement. Thirteen patients from the case and control groups developed respiratory failure
\end{abstract}

Introduction:

Intravenous immunoglobulin (IVIg) is a drug that has been used successfully with proven efficacy in the management of Guillain barre syndrome (GBS) in the developed countries. This drug is not manufactured in our country and has to be imported. Therefore, it is being used sporadically in few cases in our country since last 2 3 years by the affordable patients. So far, no case control study has been done in our country. Therefore, this study was designed to evaluate the efficacy of IVIg, feasibility of cost effectiveness of using this drug in our population. This will act as guideline for further study in large scale and consequently steps will be taken to make this drug easily available at lower cost in our country.

Guillain barré syndrome is an important cause of acute paralysis, yet the pathogenesis has still not been fully

a. Dr. Md. Mahbubur Rahman, Associate Professor of Neuromedicine, Holy Family Red Crescent Medical College Hospital, Dhaka

b. Dr. Kafiluddin Ahmed, Assistant Professor of Neuromedicine, Rajshahi Medical College Hospital, Rajshahi

Address of Correspondence: Dr. Md. Mahbubur Rahman, Associate Professor of Neuromedicine, Holy Family Red Crescent Medical College Hospital, Dhaka, Phone: 01713043103

Received: 8 January, 2009

Accepted: 22 February, 2010 requiring ICU support. Cerebrospinal fluid study showed albumin cytological dissociation. Nerve conduction study showed features of demyelination, axonal loss or both.

There was significant improvement of GBS patients treated with IVIg in respect of respiratory function, muscle tone, muscle power, jerks and autonomic function. ICU stay of patients treated with IVIg was significantly shorter. Final outcome of patients treated with IVIg showed one death. There was no death in control group. The patient died probably due to severity of disease and/or comorbid disease.

Key words: Intravenous Ig, Guillain barre syndrome

(J Bangladesh Coll Phys Surg 2010; 28: 81-85)

elucidated and specific evidence based consensus management guideline have not been developed ${ }^{1}$. Several recent studies have investigated whether there are any particular factor that might predict the course of illness and thereby dictate the optimal treatment. IVIg has been shown to have beneficial effect on the course of GBS.

Guillain barre syndrome is characterized by symmetrical flaccid ascending paralysis, areflexia and albuminocytological dissociation in cerebrospinal fluid $(\mathrm{CSF})^{2}$. The disease may be difficult to diagnose at the onset, because of the characteristic changes of slowed nerve conduction and increased spinal fluid protein may be delayed. Early diagnosis is important as prompt intervention using plasmapheresis or IVIg can arrest or reverse the disease process ${ }^{3}$.

Although the clinical term GBS has remained a convenient and useful designation, electrodiagnostic and pathologic studies indicate that there are different pattern with this syndrome. Most common is acute inflammatory demyelinating polyneuropathy (AIDP). Other varieties are acute motor axonal neuropathy (AMAN), acute motor sensory axonal neuropathy (AMSAN) and Miller Fisher syndrome (MFS). 
Approximately two third of the patients report preceding event, most frequently an upper respiratory tract infection (URTI) or gastrointestinal tract (GIT) infection, surgery or immunization 14 weeks before the onset of symptoms ${ }^{4,5}$. The agent responsible for the prodromal illness frequently remains unidentified. Specific infection linked to GBS includes cytomegalovirus (CMV), Epstein Barr virus (EBV), Varicella Zoster virus, hepatitis A\&B, human immunodeficiency virus (HIV) and mycloplasma. The mode of common identifiable bacterial organisms responsible for GBS, particularly its axonal form is Campylobacter jejuni, a curved gram negative rod, which is a frequent cause of bacterial enteritis worldwide. Evidence of C. jejuni infection from stool culture or serological test was found in $26 \%$ patients with GBS admitted to hospitals in the United Kingdom ${ }^{6}$.

\section{Materials and Methods:}

The present case control observational study was carried out in the Intensive Care Unit, Department of Neurology, Bangabandhu Sheikh Mujib Medical University (BSMMU), Dhaka, during January 2004 and June 2005.

Study design: This study consisted of the following components:

1) Selection of GBS patients based on criteria as mentioned below

Features required for diagnosis

a) Progressive weakness in both upper and lower limbs

b) Areflexia

Features strongly supporting the diagnosis

a) Progression of symptoms over days to 4 weeks

b) Relative symmetry of symptoms

c) Mild sensory symptoms or signs

d) Cranial nerve involvement, specially bilateral weakness of facial muscles

e) Recovery beginning 24 weeks after progression ceases

f) Autonomic dysfunction

g) Absence of fever at the onset

h) Elevated CSF protein with $<10 /$ cells/cumm

i) EDX features of nerve conduction slowing or block
2) Sampling technique: Stratified purposive sampling

3) Selection of patients indicated for IVIg therapy (a) severity of illness, and (b) economic status

4) Treatment given with IVIg within 2 weeks of illness

5) Dose of IVIg was $0.4 \mathrm{~g} / \mathrm{kg}$ body weight/day for 5 days

6) Follow up patients after 15 days, 1 month and 3 months

7) Analysis of the results

Subjects: A total number of 20 GBS patients fulfilling the inclusion criteria were selected for this study as case and treated with IVIg, and 20 GBS patients who received only symptomatic treatment but did not receive IVIg were selected as control.

Methods: Detailed clinical examination, medical history, history of URTI, gastroenteritis, family history, thorough physical examination, pulse, blood pressure, cardiovascular and respiratory system were examined. Detailed neurological examination, including fundus examination were done. All information and findings were noted in predesigned data collection sheet. NCS and CSF studies were done.

Treatment modalities were symptomatic and IVIg within 2 weeks of GBS.

Collected data were compiled and appropriate statistical analyses were done using computerbased software (SPSS). P value $<0.05$ was taken as minimum level of significance.

\section{Results:}

Majority of cases had history of respiratory tract infection (60\%), 30 percent diarrhoea, while in the control group, 55 percent had respiratory tract infection and 35 percent had diarrhoea. There is no significant difference of illness between case and control groups (Table I).

Improvement after treatment with IVIg was reviewed after 15, 30 and 90 days of treatment. There was significant improvement in respiratory function, muscle tone, muscle power, jerks and autonomic functions after 15, 30 and 90 days of treatment in case group in comparison with control group. Respiratory function 
was assessed by forced vital capacity (FVC) and respiratory rate (Table II).

Improvement of muscle power after 90 days of treatment showed that $8(40 \%)$ cases and 5 (25\%) controls improved into grade IV, and three of the cases and one control improved into grade V, 7 (35\%) cases and 4 (16\%) controls were found in grade III. There was significant improvement in case group after 90 days of treatment in comparison with control group (Table III).

Muscle tone and jerks also improved after 90 days of treatment. After 90 days, muscle tone in 8 (40\%) control group and 18 (90\%) case group became normal. Jerks also improved to normal in 10 (50\%) controls and 20 (100\%) cases (Table IV).

On admission 9 cases and 5 controls were in ICU. After 15 days, none of the cases and one control group was in ICU. This value is statistically significant $(\mathrm{P}<0.05)$ (Table V).

Final outcome shows that after treatment with intravenous immunoglobulin, one (5\%) case expired. There was no fatality in the control group. This may be due to severity of the disease and other comorbid condition (aspiration pneumonia) (Table VI).

\section{Table-I}

\begin{tabular}{|c|c|c|c|c|c|}
\hline \multicolumn{6}{|c|}{ History of preceding illness (1 4 weeks) } \\
\hline \multirow[t]{2}{*}{ Illness } & \multicolumn{2}{|c|}{$\begin{array}{l}\text { Control } \\
(\mathrm{n}-20)\end{array}$} & \multicolumn{2}{|c|}{$\begin{array}{l}\text { Case } \\
(\mathrm{n}-20)\end{array}$} & \multirow[t]{2}{*}{ P value } \\
\hline & No. & (\%) & No. & (\%) & \\
\hline Diarrhoea & 6 & $(30.0)$ & 7 & $(35.0)$ & \\
\hline $\begin{array}{l}\text { Respiratory } \\
\text { tract infection }\end{array}$ & 12 & $(60.0)$ & 11 & $(55.0)$ & $>0.50^{\mathrm{ns}}$ \\
\hline Others & 2 & $(10.0)$ & 2 & $(10.0)$ & \\
\hline
\end{tabular}

Chi-square test, ns = Not significant

Table-II

\begin{tabular}{|c|c|c|c|c|c|}
\hline \multicolumn{6}{|c|}{ Comparison of improvement between control and case } \\
\hline \multirow[t]{2}{*}{ Improvement } & \multicolumn{2}{|c|}{$\begin{array}{c}\text { Control } \\
\text { (n 20) }\end{array}$} & \multicolumn{2}{|c|}{$\begin{array}{l}\text { Case } \\
\text { (n 20) }\end{array}$} & \multirow[t]{2}{*}{ P value } \\
\hline & No. & $(\%)$ & No. & $(\%)$ & \\
\hline Respiratory function & & (n 4$)$ & & (n 9) & \\
\hline After 15 days & 1 & $(25.0)$ & 8 & $(88.9)$ & $<0.05^{*}$ \\
\hline After 30 days & 4 & $(100.0)$ & 9 & $(100.0)$ & $>0.10^{\text {ns }}$ \\
\hline \multicolumn{6}{|l|}{ Muscle tone } \\
\hline After 15 days & 0 & & 2 & $(10.0)$ & \\
\hline After 30 days & 5 & $(25.0)$ & 15 & $(75.0)$ & $<0.05^{*}$ \\
\hline \multicolumn{6}{|l|}{ Muscle power } \\
\hline After 15 days & 0 & & 2 & $(10.0)$ & \\
\hline After 30 days & 7 & $(35.0)$ & 18 & $(90.0)$ & $<0.05^{*}$ \\
\hline \multicolumn{6}{|l|}{ Jerks } \\
\hline After 15 days & 0 & & 3 & $(15.0)$ & \\
\hline After 30 days & 7 & $(35.0)$ & 19 & $(95.0)$ & $<0.05^{*}$ \\
\hline \multicolumn{6}{|c|}{ Autonomic dysfunction } \\
\hline After 15 days & 3 & $(15.0)$ & 14 & $(70.0)$ & $<0.05^{*}$ \\
\hline After 30 days & 20 & $(100.0)$ & 20 & $(100.0)$ & \\
\hline
\end{tabular}

$\mathrm{Z}$ test, ns $=$ Not significant, $*=$ Significant 
Table-III

\begin{tabular}{|c|c|c|c|c|c|}
\hline \multicolumn{6}{|c|}{ Improvement of muscle power after 90 days } \\
\hline \multirow[t]{2}{*}{ Power } & \multicolumn{2}{|c|}{$\begin{array}{c}\text { Control } \\
\text { (n 20) }\end{array}$} & \multicolumn{2}{|c|}{$\begin{array}{l}\text { Case } \\
\text { (n 20) }\end{array}$} & \multirow[t]{2}{*}{$P$ value } \\
\hline & No. & (\%) & No. & (\%) & \\
\hline G-0 & 0 & & 0 & & \\
\hline G-1 & 2 & $(10.0)$ & 0 & & \\
\hline G-2 & 8 & $(40.0)$ & 2 & (10.0) & \\
\hline & & & & & $<0.05^{*}$ \\
\hline G-3 & 5 & $(25.0)$ & 5 & $(25.0)$ & \\
\hline G-4 & 4 & $(16.0)$ & 8 & $(40.0)$ & \\
\hline G-5 & 1 & $(5.0)$ & 5 & (25.0) & \\
\hline
\end{tabular}

Chi square test, $*=$ Significant

Table-IV

\begin{tabular}{|c|c|c|c|c|c|}
\hline \multicolumn{6}{|c|}{ Improvement of other motor functions after 90 days } \\
\hline \multirow[t]{2}{*}{$\begin{array}{l}\text { Motor } \\
\text { functions }\end{array}$} & \multicolumn{2}{|c|}{$\begin{array}{l}\text { Control } \\
\text { (n 20) }\end{array}$} & \multicolumn{2}{|c|}{$\begin{array}{l}\text { Case } \\
\text { (n 20) }\end{array}$} & \multirow[t]{2}{*}{ P value } \\
\hline & No. & (\%) & No. & (\%) & \\
\hline Muscle tone & 8 & $(40.0)$ & 18 & $(90.0)$ & $>0.05^{\mathrm{ns}}$ \\
\hline Jerks & 10 & (50.0) & 20 & $(100.0)$ & $>0.50^{\mathrm{ns}}$ \\
\hline
\end{tabular}

$\mathrm{Z}$ test, ns = Not significant

Table-V

\begin{tabular}{lcccccc}
\multicolumn{7}{c}{ ICU stay for control and case } \\
ICU stay & \multicolumn{2}{c}{$\begin{array}{c}\text { Control } \\
\text { (n 5) }\end{array}$} & No. & Case & P value \\
& No. & $(\%)$ & No. & $(\%)$ & \\
\hline Up to 7 days & 5 & $(100.0)$ & 9 & $(100.0)$ & $<0.05^{*}$ \\
Up to 15 days & 4 & $(80.0)$ & 4 & $(44.4)$ & \\
More than 15 days & 1 & $(20.0)$ & 0 & & & \\
\hline
\end{tabular}

$\mathrm{Z}$ test, $*=$ Significant

Table-VI

\section{Final outcome of treatment}

\begin{tabular}{|c|c|c|c|c|}
\hline \multirow[t]{2}{*}{ Outcome } & \multicolumn{2}{|c|}{$\begin{array}{c}\text { Control } \\
\text { (n 20) }\end{array}$} & \multicolumn{2}{|c|}{$\begin{array}{l}\text { Case } \\
\text { (n 20) }\end{array}$} \\
\hline & No. & $(\%)$ & No. & $(\%)$ \\
\hline Survived & 20 & $(100.0)$ & 19 & (95.0) \\
\hline Expired & 0 & & 1 & (5.0) \\
\hline
\end{tabular}




\section{Discussion:}

This was an observational study which included 40 subjects. The study population was equally divided in two groups. One was control group having GBS with symptomatic treatment only. Another was case group having GBS treated with IVIg. The study was carried out to see the improvement of GBS after specific therapy with IVIg.

In our study, 56\% subjects of case group had history of preceding upper respiratory tract infection and 35\% had the history of diarrhoea, while in the control group, $60 \%$ had respiratory tract infection and 30\% had diarrhoea. This finding is consistent with studies by Ho et al. ${ }^{7}$.

Patients were assessed after 15, 30 and 90 days of treatment with or without intravenous immunoglobulin. Parameters were respiratory function, muscle tone, muscle power, jerks and autonomic function. In all modalities, there was significant improvement in the case group than the control group. This is probably due to blockage of action of antibody to nerve. This study is consistent with the findings by Hughes et al. ${ }^{8}$ and Hughes et al. ${ }^{9}$.

There was significant difference in the duration of ICU stay between case and control groups. Up to 7 days of treatment, 9 in the case group and 5 in the control group were in ICU. At 15 days, the number of patients in ICU were 4 in both groups. After 15 days, only one patient stayed in the ICU, but none from case group was in ICU. This signifies that ICU stay also become shorter by giving IVIg. This study correlates with the findings done by Tekgul et al. ${ }^{10}$.

In our study consisting of 40 patients, 20 in control group and 20 in case group, only one in the case group expired (5\%) and cause of death was apiration pneumonia. No fatality was seen in the control group. This may be due to existing comorbid conditgion. It may also be due to severity of disease. This finding is consistent with Sater $^{10}$.

\section{Conclusion:}

There was significant improvement of Guillain Barré syndrome patients treated with intravenous immunoglobulin in respect to respiratory function, muscle tone, muscle power, jerks and autonomic function. Also ICU stay was shorter.
Intravenous immunoglobulin plays beneficial role in the improvement of case group with respect to control group. Further research is needeed in the treatment of GBS two weeks after onset of the condition.

\section{Limitation of the study}

Number of cases was less because of inability of the patients to procure this costly drug. Local pharmaceutical companies could be encouraged to ensure availability of the drug at a cheaper rate.

\section{References:}

1. van Doorn PA, Ruts L, Jacobs B. Clinical features, pathogenesis, and treatment of Guillain Barre syndrome. Lancet Neurol 2008; 7:939 50.

2. Guillain G, Barre JA, Strohl A. Sur un syndrome de radienlo nevrite avee hyperalbuminose du liquide cephalora chidien sans reaction cellulaire; remarques sur les caracters clinique at graphiques des reflexes turdinex. Bull Soc Med Hosp Paris 1916; 40:1462 70 .

3. Hughes RA, Raphael JC, Swan AV, van Doorn PA. Intravenous immunoglobulin for Guillain Barre syndrome. Cochrane Database Syst Rev 2006; 1:CD002063.

4. Guillain Barré Syndrome Study Group. Guillain Barre syndrome: an Italian multicentre case control study. Neurol Sci 2000; 21:229 34 .

5. Hadden RD, Karch H, Hartung HP. Preceding infections, immune factors, and outcome in Guillain Barre syndrome. Neurology 2001; 56:758 65.

6. Rees J, Gregson NA, Hughes RAC. Anti ganglioside $\mathrm{GM}_{1}$ antibodies in Guillain Barre syndrome and their relationship to Campylobacter jejuni infection. Ann Neurol 1995; 38:809 16.

7. Ho TW, Mishee B, Lic Y, Gao CY, Bornblath DR, Griffin JW, et al. Guillain Barre syndrome in northern China: relationship to Campylobacter jejuni infection and antiglycolipid antibodies. Brain 1995; 118:597 605.

8. Hughes RA, Swan AV, Raphael JC, Annane D, van Knoingsveld R, van Doorn PA. Immunotherapy for Guillain Barre syndrome: a systematic review. Brain 2007; 130:2245 57.

9. Hughes RAC, Raphael JC, Swan AV, va Doorn PA. Intravenous immunoglobulin for Guillain Barre syndrome. The Cochrane Collaboration. Cochrane Library, 2009, issue 1.

10. Tekgul H, Kutukenler N, Caglayan S, Tutuncuoglu S. Proinflammatory cytokines, lympocyte subsets and intravenous immunoglobulin therapy in Guillain Barre syndrome 1996; 40:357 63.

11. Sater RA. Treatment of Guillain Barre syndrome with intravenous immunoglobulin. Neurology 1998; 51(Suppl 5):S9 15. 